THE ROLE OF PERCEIVED THREAT TO FREEDOM OF CHOICE IN CHILDREN'S PREFERENCE FOR SCARCITY

\author{
by \\ Kathryn Harper \\ Bachelor of Arts, Honours, University of Guelph, 2013

\begin{abstract}
A thesis
presented to Ryerson University

in partial fulfillment for the degree of
\end{abstract} \\ Master of Arts \\ in the program of \\ Psychology
}

Toronto, Ontario, Canada, 2017

C C Kathryn Harper, 2017 


\section{AUTHOR'S DECLARATION FOR ELECTRONIC SUBMISSION OF A THESIS}

I hereby declare that I am the sole author of this thesis. This is a true copy of the thesis, including any required final revisions, as accepted by my examiners.

I authorize Ryerson University to lend this thesis to other institutions or individuals for the purpose of scholarly research.

I further authorize Ryerson University to reproduce this thesis by photocopying or by other means, in total or in part, at the request of other institutions or individuals for the purpose of scholarly research.

I understand that my thesis may be made electronically available to the public. 


\title{
THE ROLE OF PERCEIVED THREAT TO FREEDOM OF CHOICE IN CHILDREN'S PREFERENCE FOR SCARCITY
}

\author{
Kathryn Harper \\ Master of Arts in Psychology \\ Ryerson University
}

2017

\begin{abstract}
The present research investigated the role of perceived threat to freedom of choice in children's development of preference for scarcity. In two experiments, 5- to 7-year-olds assisted a fictional agent in choosing between relatively scarce versus abundant toys in a "virtual shop." Experiment 1 investigated the role of extremity of scarcity in children's preference for scarcity, while Experiment 2 investigated the role of the presence of competition. These two factors were anticipated to activate perceived threat to freedom to choose the scarce objects, resulting in motivational arousal to choose the scarce objects. Overall, a preference for scarcity increased with age. When threat to freedom of choice was induced, 7-year-olds showed a robust preference for scarcity in both experiments. The findings are discussed in the context of reactance theory and other factors influencing children's patterns of responses, including prosociality. This research contributes to our understanding of children's use of statistical information.
\end{abstract}

Key words: scarcity, threat to freedom of choice, psychological reactance 


\section{Acknowledgements}

Sincere thanks are extended to the children who participated in this research and their families, and to the research assistants in the Early Childhood Cognition Lab, whose support and hard work made this project possible. I would also like to thank Dr. Julia Spaniol and Dr. Lixia Yang for their service on my thesis committee, and for providing guidance and constructive feedback. Finally, I would like to express my deepest gratitude to Dr. Lili Ma for her supervision, support, and mentorship. This study is part of an NSERC Discovery Grant to Lili Ma. 


\section{Table of Contents}

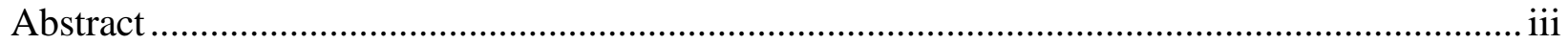

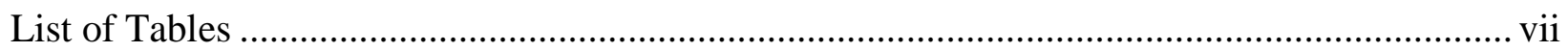

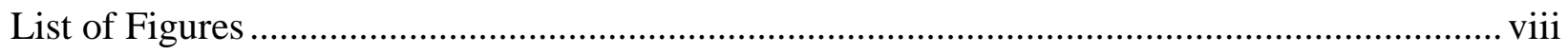

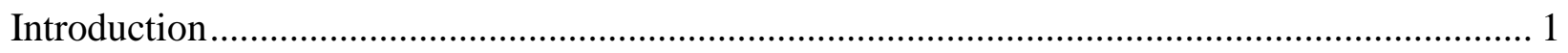

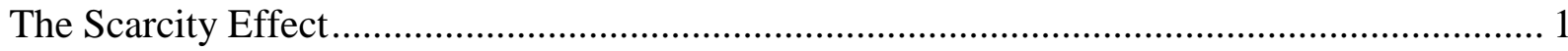

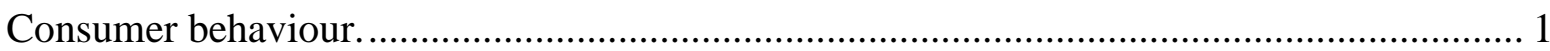

Impact of different causes of scarcity. .............................................................. 3

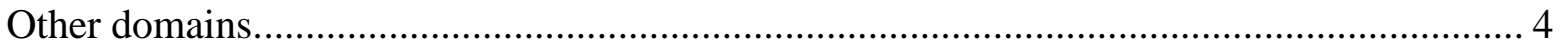

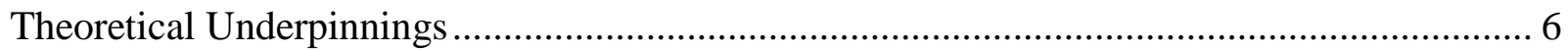

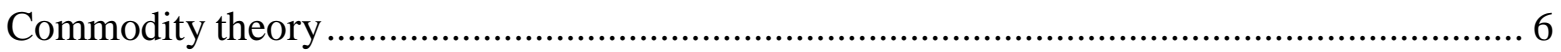

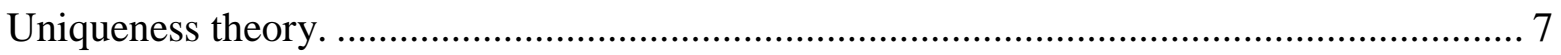

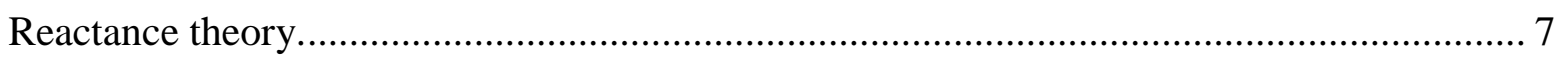

Reactance theory in the developmental context...................................................... 9

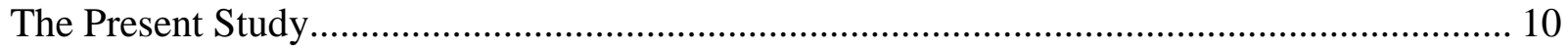

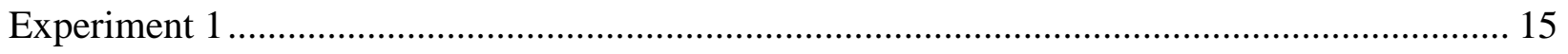

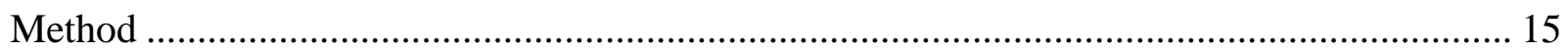

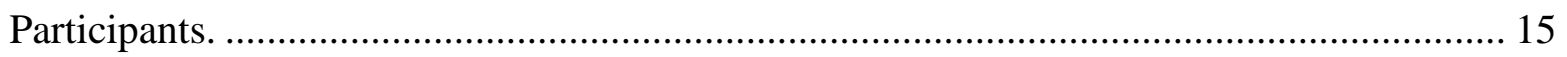

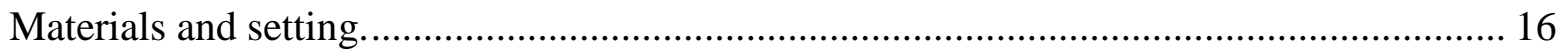

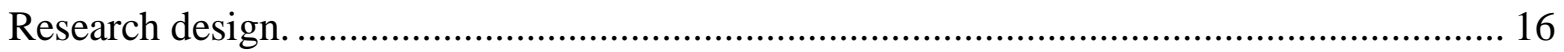


Procedure.

Coding.

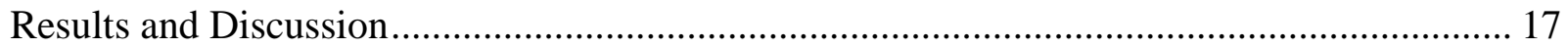

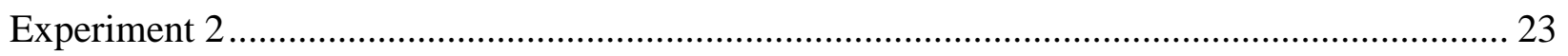

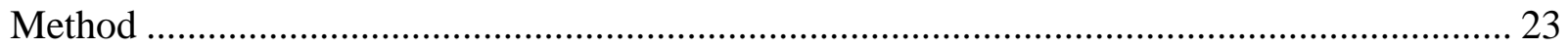

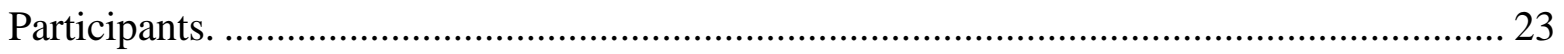

Materials, setting, and research design............................................................................ 24

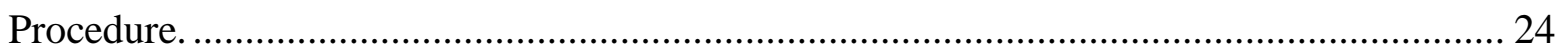

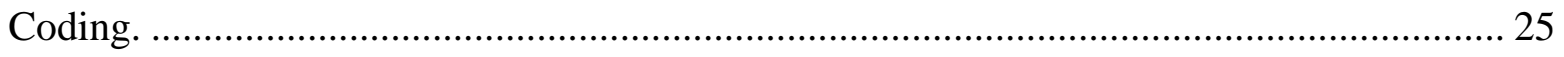

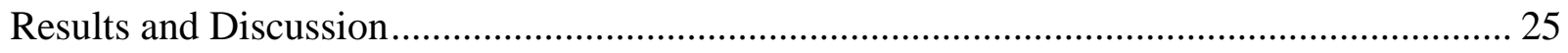

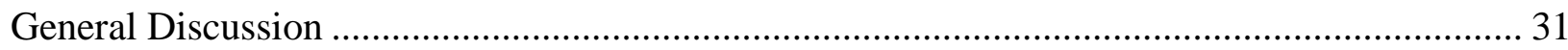

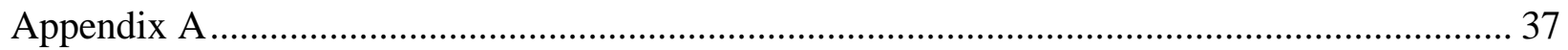

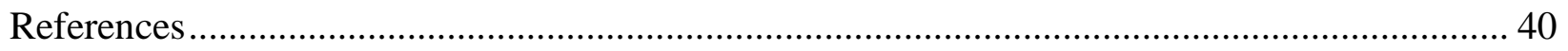




\section{List of Tables}

Table 1: Children's explanations on judgment tasks in Experiment 1 (by condition, age group,

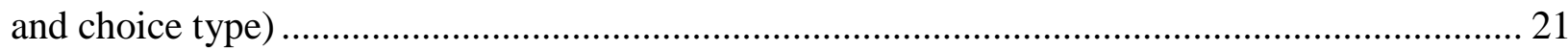

Table 2: Children's explanations on decision tasks in Experiment 1 (by condition, age group, and

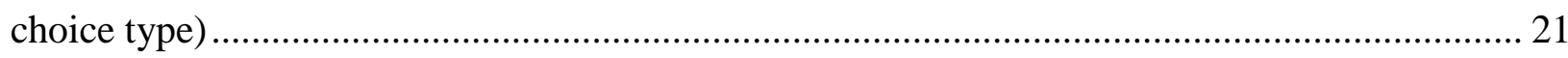

Table 3: Children's explanations on judgment tasks in Experiment 2 (by condition, age group,

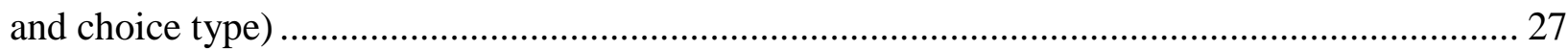

Table 4: Children's explanations on decision tasks in Experiment 2 (by condition, age group, and choice type) 28 


\section{List of Figures}

Figure 1: Sample trials from Experiment 1.................................................................. 16

Figure 2: Proportion of scarce objects chosen in Experiment 1 .......................................... 19

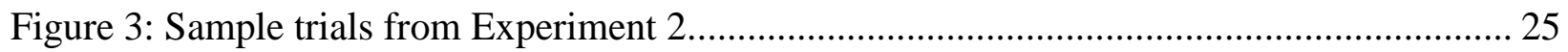

Figure 4: Proportion of scarce objects chosen in Experiment 2 ....................................... 26 
The Role of Perceived Threat to Freedom of Choice in Children's Preference for Scarcity

\section{Introduction}

Preferences and decision-making processes are pivotal aspects to understanding human behaviour. Much research has focused on how adults form preferences and make decisions, including in the context of preference for scarce resources and decisions to favour or purchase scarce commodities, perhaps because economic and purchasing decisions are significant components of adult life. However, research into the impact of scarcity on children's same preferences and decisions has received substantially less research attention. As future consumers, and as current potential influencers of families' purchasing decisions, it is equally important to consider these same preferences and decisions amongst children. Furthermore, research into young children's use of scarcity information can more broadly elucidate children's use of statistical information in other instances of judgment and decision-making.

\section{The Scarcity Effect}

Consumer behaviour. One significant cue that adults use in their evaluations of desirability of resources is scarcity. The scarcity effect is the tendency for people to prefer rare objects in their environment over more abundant ones (Lynn, 1991). Described as a "naïve economic theory" (Lynn, 1992, p. 67), this preference for scarce objects over more abundant ones has been well documented in adults, particularly in the context of consumer behaviour and purchasing of consumer goods (e.g., Gierl \& Huettl, 2010; Lee, Oh, \& Jung, 2014; Verhallen \& Robben, 1994). The scarcity effect has also been observed in food and beverage domains, with valuations of comestibles being similarly influenced by perceptions of scarcity as other commodities. For example, wines that are scarce in stores are viewed as higher quality than more 
abundant wines (van Herpen, Pieters, \& Zeelenberg, 2014). Cookies that are scarce are similarly seen as more desirable than more abundant varieties (Worchel, Lee, \& Adewole, 1975).

Research has suggested that scarce objects may be assumed to be more expensive than more abundant objects (e.g., Lynn, 1989; Lynn, 1992). Furthermore, Lynn (1992) notes that assumed expensiveness leads to higher status of a commodity, helping to explain the consumer appeal of scarce products. These types of beliefs extend to anticipated price appreciation, with scarce objects (for example, rare collectables) being expected to appreciate in price more so than abundant ones (Lynn \& Bogert, 1996). Scarcity increases perceptions of value in both high-cost and low-cost products (Suri, Kohli, \& Monroe, 2007).

The implication or explicit mention of scarcity of a product is a commonly-used method in the marketing context, and for good reason - purchasing intent increases with the perception of scarcity (Jung \& Kellaris, 2004). Interestingly, while scarcity has been found to increase product valuations, this effect is diminished when emphasis of scarcity is viewed as a sales trick, perhaps on the basis of the vending company's reputation, or the availability of cognitive resources to detect marketing ploys (Lee et al., 2014).

Previous research has suggested that some cross-cultural differences exist in the demonstration of the scarcity effect, with those from individualistic cultures showing a stronger preference for scarcity than do those from collectivistic cultures (Jung \& Kellaris, 2004). This is posited to result from differential communication and persuasion styles, with collectivist cultures focusing more on hierarchies and implicit messages than individualistic cultures (Jung \& Kellaris, 2004). This is demonstrated by marketing techniques utilized in these cultures - in individualistic cultures, persuasive messages tend to focus on testimonials, demonstrations, and other objective techniques. In collectivistic cultures, persuasive messages tend to appeal to the 
audience on a more human level and aim to build a relationship between brand and consumer (Jung \& Kellaris, 2004). Potential cross-cultural differences in how individuals distribute scarce resources have also been noted, with some influence of whether individuals are raised in a market-driven or communist society (Kemp \& Bolle, 1999). However, Kemp and Bolle (1999) note that upbringing in market-driven or communist societies does not fully explain preferences for distributing scarce resources, with other factors contributing to preferences for distribution of goods, including whether goods are considered to be luxuries or necessities (Kemp, 1998).

Impact of different causes of scarcity. The impact of scarcity on preference for products or resources is further qualified by the cause of scarcity. For example, when scarcity of a product is due to market conditions (i.e., low supply of or high demand for the product), valuations of the product increase; however, accidental and/or temporary scarcity does not have the same impact on product valuations (Verhallen, 1982). Research has shown that product valuations are especially inflated when products are scarce due to both low supply and high demand (Verhallen \& Robben, 1994). Interestingly, this research has also shown that preference for scarcity may erode when individuals feel that their choices impact others - in one study, participants who believed other people would be able to take a product home after they themselves chose a product to keep, chose away from the scarce product, in order to leave it for other, more interested participants (Verhallen \& Robben, 1994). This suggests that social constraints play a role in how preference for scarcity may manifest in real-world situations.

Furthermore, Gierl and Huettl (2010) found that products consumed conspicuously - for example, mobile phones and laptop computers - experience greater valuations as a result of scarcity caused by low supply of the product. Products consumed inconspicuously - such as yogurt and bars of soap - experience increased valuations as a result of scarcity resulting from 
higher demand. Similarly, Ku, Kuo, Yang, and Chung (2013) differentiate between utilitarian and hedonic products, and note that valuations of utilitarian products are inflated when scarcity is a result of high demand, but that this is not the case with hedonic products. Valuations of hedonic products are, however, inflated as a result of scarcity caused by low supply. This may be partly explained by the finding that, when consumers are driven by a goal to be unique, supplycaused scarcity especially increases desirability (van Herpen et al., 2014). Because hedonic and conspicuously-consumed products are, almost by definition, consumed in front of others, it makes theoretical sense that products that are scarce due to low supply (meaning others likely have not and cannot obtain them) would appeal to the uniqueness-seeker.

The impact of a change in scarcity status on commodity desirability is also worth discussing. While it is true that scarce items are consistently deemed more desirable than more abundant ones, research has also shown that products that were abundant and have become scarce are valued more highly than those that are consistently scarce (Worchel et al., 1975). Similarly, products that were scarce but become abundant are regarded as less desirable than those that are consistently abundant. Dynamic scarcity status may therefore imply much about surrounding market conditions (i.e., levels of supply and demand) and affect product valuations accordingly.

Other domains. Interestingly, scarcity is also thought to increase perceptions of value of concepts other than commodities. In line with Brock's 1968 commodity theory, discussed below, Brock and Brannon (1992) posit that traits and skills are conceptually similar enough to commodities that they are also valued on the basis of their relative scarcity. Commodities can be defined as entities that can be owned, are useful, and whose ownership can be transferred from one person to another (Brock, 1968). Including traits, skills, information, and conditions under 
the umbrella of commodities may seem unusual, but these concepts, just like physical commodities, are able to be possessed, can be useful/impactful, and can be imitated, emulated, imparted, and/or shared (Brock \& Brannon, 1992). Because of these similarities to the original definition of physical commodities, it makes theoretical sense for entities other than physical commodities to be valuated, at least in part, on the basis of their relative scarcity or abundance.

Empirical research supports this idea that scarcity impacts perceived value of concepts aside from physical commodities. One study found that, when participants were led to believe that they possessed high levels of a fictitious personal trait, and that said trait was uncommon in the general population, they evaluated it as more desirable and valuable to possess (Brannon $\&$ Brock, 2010). Another study found that priming participants with words related to death elicits awareness of the shortness, or scarcity, of life itself. This salience of the scarcity of life was found to elicit higher ratings of life satisfaction (King, Hicks, \& Abdelkhalik, 2009). Scarcity has also been found to make messaging more persuasive. Fromkin and Brock (1971) found that participants who were exposed to messaging that is low in availability (i.e., not many people heard the message) but high in demand (i.e., the message is relevant and/or interesting to many people) were more persuaded by that messaging than by messages that were more freely available and/or less in demand. Similarly, other research has shown that individuals are motivated to gain access to information that is censored or otherwise limited in accessibility (Worchel, 1992), suggesting that information is viewed as more valuable or desirable when it is difficult to obtain.

Additionally, scarcity is thought to increase extremity of evaluation for entities of negative valence as well as those of positive valence (Brock \& Brannon, 1992). Just as desirable consumer products or personal traits or experiences are seen as more desirable when scarce, 
negative entities and experiences have more negative perceptions when they are believed to be rare. Research has shown that individuals view detrimental health conditions that are uncommon in the general population as more aversive than detrimental health conditions that are more common (Ditto \& Jemmott, 1989). Scarcity has therefore been found to be a salient cue across a wide variety of contexts.

\section{Theoretical Underpinnings}

The mechanisms underlying the scarcity effect will be discussed in the context of three

prominent theories: commodity theory (Brock, 1968), uniqueness theory (Fromkin \& Snyder, 1980), and reactance theory (Brehm, 1966).

Commodity theory. Commodity theory, put forth by Brock (1968), posits that the economic principles of supply and demand are responsible for the well-observed preference for scarce resources. The theory proposes that commodities - entities that can be owned, are useful, and whose ownership can be transferred from one person to another - are valued on the basis of their availability or unavailability, such that when commodities are scarce due to low supply and/or high demand, they are valued more highly and perceived as more desirable. This helps to explain the ever-popular sales tactics of claiming dwindling supplies of products and launching limited-time offers in successful attempts to boost product sales (Lynn, 1991).

Brock and Brannon (1992) further expand upon this theory through broadening the scope of entities that are impacted by market forces and proposing that relative scarcity polarizes valuations and perceptions, regardless of valence. As such, the market forces of supply and demand are also thought to increase the value of concepts outside of physical artifacts (Brock \& Brannon, 1992). As noted above, traits (Brannon \& Brock, 2010), messaging (Fromkin \& Brock, 
1971), and even life itself (King et al., 2009) all receive more positive valuations when they are perceived as scarce.

Uniqueness theory. Uniqueness theory, outlined by Fromkin and Snyder (1980) and Lynn (1991), is also useful in explaining the scarcity effect. Uniqueness theory was built off of the principles of commodity theory (Brock, 1968), and expands on it, positing that humans are driven to distinguish themselves from peers and to identify themselves as distinct from others. This suggests that preference for scarcity (in particular, scarce commodities; Snyder, 1992) relates to a person's desire to stand out and be distinct from one's peers. In the context of the scarcity effect, acquisition and display of scarce objects may serve as a way of differentiating oneself from one's peers (Tian, Bearden, \& Hunter, 2001). Verhallen and Robben (1994) found that books that are scarce as a result of market conditions are perceived to be more unique than comparable books that were freely available or accidentally/temporarily scarce. As noted above, consumers' uniqueness-driven goals are thought to increase desire for scarce products specifically those products made scarce due to low supply (van Herpen et al., 2014). Uniqueness theory speaks to individual differences in people's need to be unique, and is especially useful in explaining the scarcity effect when applied to individuals who are particularly high in need for uniqueness (Snyder, 1992).

Reactance theory. Reactance theory pertains to people's behaviour when freedom of choice is limited or restricted, and posits that when an individual's freedom is challenged or removed, the individual will take action to restore that freedom (Brehm, 1966). Psychological reactance can be defined as "a motivational state aroused when real or perceived personal freedoms are threatened, reduced, or eliminated" (Woller, Buboltz, \& Loveland, 2007, p. 15). Reactance can manifest in many ways, depending on the context that is causing feelings of threat 
to freedom, including both internalizing and externalizing behaviours (Van Petegem, Soenens, Vansteenkiste, \& Beyers, 2015).

Research into this phenomenon has found demographic differences in levels of reactance between groups. In considering reactance as a trait, Woller et al. (2007) found that, in a large college sample, men show more reactance than women and members of visible minority groups show higher reactance than Caucasian individuals. The authors also found a U-shaped effect of age on levels of reactance, with younger and older individuals generally showing more reactance than middle-aged individuals.

Experimental research has also documented the effects of psychological reactance. In one study, participants were asked to rate the attractiveness of four pieces of music, twice, separated by one day. Participants were told that, at the completion of the second rating session, they would be allowed to take home a recording of one of the pieces of music. Participants provided their initial ratings of the pieces, and then returned the next day to re-rate the pieces. Before the second rating session, however, participants were told that the recording of the piece of music that they had rated third-best the day before had, for some reason, not been shipped, and was therefore unavailable to take home. Participants then listened to the pieces again and provided their second round of ratings. Results showed that participants significantly increased their ratings of this now-eliminated choice, demonstrating reactance in the face of barriers to freedom of choice (Brehm, Stires, Sensenig, \& Shaban, 1966).

In the present context, scarcity of an object in one's environment can be seen as a threat to one's freedom to possess that object. This results in motivational arousal to prefer scarce objects due to a perceived threat to freedom of choice. As noted above, research has shown that artifacts become more desirable when they are made unavailable to obtain, when individuals at 
one time did have freedom to obtain the artifact (Brehm et al., 1966). Research has also extended principles of reactance theory and its role in the attractive nature of scarcity to concepts aside from artifacts. Worchel (1992) demonstrated that, in the face of personal censorship of a message, individuals tend to be more highly motivated to hear the censored message than those who did not experience personal censorship. That is to say, individuals who experience a lack of freedom to hear a message as a result of personal restriction are highly motivated to gain access to that difficult to obtain, or scarce, message. Wright (1992) similarly applies reactance theory and scarcity to task achievement; in completing tasks of varying levels of difficulty, participants ranked more difficult task outcomes as more valuable. This further suggests that when entities are difficult to obtain, psychological reactance leads to higher valuations of those entities.

Reactance theory in the developmental context. In the developmental context, prior research has investigated children's reactions to perceived threat to freedom of choice, and has found evidence to suggest that children take actions to restore feelings of freedom when they perceive a threat to their freedom. For example, previous research has demonstrated 2-year-olds' desire and motivation to obtain objects to which their access is physically impeded (Brehm \& Weinraub, 1977). Additionally, parental disapproval has also been shown to increase 12-yearolds' desire for products (Rummel, Howard, Swinton, \& Seymour, 2000). Moreover, Van Petegem et al. (2015) found that controlling parenting styles are associated with higher rates of externalizing and internalizing behaviours in adolescents, in reaction to removal of and restrictions on freedom. Egan, Bloom, and Santos (2010) furthermore found a marginally significant preference among 4-year-olds for toys that were not given to them by experimenters, suggesting that children desire and are motivated to obtain things they feel are being kept from 
them, or that are difficult to obtain. The existing research therefore suggests that, in the face of threat to freedom, children are motivated to restore feelings of freedom.

Reactance theory, in the context of the scarcity effect, can therefore be posited to predict motivational arousal to prefer scarce objects due to a perceived threat to freedom of choice, with object scarcity representing threat to one's freedom to possess that object. Based on previous research findings that children are motivated to act in such a way that restores their freedom or removes the threat to their freedom, the current study aims to demonstrate the scarcity effect in childhood through the manipulation of perceived freedom of choice.

\section{The Present Study}

The scarcity effect in children has received considerably less research focus than has the impact of scarcity on adults' perceptions and behaviours. Recent research undertaken in the Early Childhood Cognition (ECC) Lab at Ryerson University has begun to explore the developmental origins of the scarcity effect, and has produced some interesting but so far inconclusive results.

In one recent study, children ages 3 through 8 years were presented with a virtual representation of unfamiliar Asian snacks and drinks that the owner of a convenience store was interested in selling. Each snack or drink was presented in two different flavours. One flavour was abundant, and the other relatively scarce (30:4). The packaging did not give any definitive clues as to what each flavour was. Children were told that other people had already tried these snacks and drinks, and were then asked to imagine that they were going to try one of each type of snack or drink, and to indicate which one they would most like to try. Results indicated that, with age, there was an increase in the likelihood of children choosing to try the scarce product. However, a robust preference for the scarce flavours was only observed in the 8-year-old 
children. Interestingly the 3- and 4-year-olds appeared to prefer the abundant flavours over the scarce ones. These findings suggest that, at least in food domains, preference for scarcity may begin to emerge in middle childhood (Ma, in preparation).

In another study, children ages 4 through 8 years were given the opportunity to "purchase" toys from a constructed toy shop, with play money earned through participation in previous tasks. Small toys, placed in cloth bags with neutral and comparable patterns, were presented in a ratio of 30:5 on each trial. The toys were placed in bags in order to mask the quality or appeal of the individual toys participants were selecting from, and ideally focusing their attention on the relative quantities. Results showed that none of the target age groups of children showed preference for scarce objects. These findings suggest that, in object domains, preference to purchase scarce products may not emerge until a later age than is observed in food domains (Ma \& Harper, in progress).

These two studies suggest that the scarcity effect may indeed emerge in childhood. However, because a preference for scarcity was not observed for 8-year-olds in the second study, there may be methodological issues with the paradigm. Compared to the "virtual shop" paradigm used in the first study, the constructed toy shop paradigm may have introduced an unduly high cognitive load into the procedure, with children focusing on the patterns of the cloth bags and speculating on the contents, rather than focusing on the relative scarcity and abundance of the toys. Therefore, the proposed research will utilize the "virtual shop" paradigm, with novel objects being presented as toys, so as to reduce this cognitive load and allow for children to focus on the relative scarcity and abundance of the objects.

It is unknown if certain experimental manipulations can be performed to induce a preference for scarce objects in early childhood. The proposed research will investigate the effect 
of perceived threat to freedom of choice on children's preference for scarce, over abundant, objects. Through the manipulation of extremity of scarcity and the introduction of the presence of competition in the procurement of scarce objects, the proposed experiments aim to elucidate the relationship between perceived threat to freedom of choice and children's development of preference for scarce resources.

The proposed experiments will employ a virtual shop paradigm, wherein children view a digital representation of a toy shop and make judgments about the toys' desirability, as well as decisions about which toy ought to be purchased. The virtual shop paradigm has a history of use in assessment and treatment of traumatic brain injury (e.g., Erez, Weiss, Kizony, \& Rand, 2013), cerebral palsy (e.g., Kirshner, Weiss, \& Tirosh, 2011), and post-stroke recovery (e.g., Rand, Katz, \& Weiss, 2007; Rand, Weiss, \& Katz, 2009) in adult and paediatric populations. It has been found to be both motivating and enjoyable for children (Erez et al., 2013), and has received positive feedback from participants in other studies (e.g., Rand et al., 2007). On the basis of these findings, there is reason to believe that the virtual shop paradigm will be engaging and enjoyable for children of the target ages of the proposed research.

The present research presupposes that children of the target ages ( 5 through 7 years) have achieved certain cognitive prerequisites for participation in the tasks: first, that children of the target ages have an understanding of basic math and concepts of quantity, including the ability to attend to quantity information and differentiate between high and low quantities; and second, that children of the target ages have an understanding of simple economic concepts, including the role of money in purchasing commodities and the effects of market forces on product sales.

To address the first presupposition, prior research indicates that children of the target age group have developed the basic numeracy skills required for the tasks. Previous research has 
indicated that basic numeracy concepts develop early in childhood, with basic number competence developing before first grade (Jordan, Kaplan, Ramineni, \& Locuniak, 2009). In fact, Feigenson, Dehaene, and Spelke (2004) assert that 6-month-old infants are capable of approximating numerical magnitudes. In a classic study by Wynn (1992), it was demonstrated that infants show surprise at incorrect arithmetic, suggesting that concepts of numeracy develop extremely early in life. In addition, it has been suggested that the mind is inherently structured to represent and process numbers (Wynn, 1998).

Interestingly, children as young as 3 years of age have been found to spontaneously attend to quantities of objects, and choose to match stimuli on the basis of numerical quantity over other characteristics. In one study, 3-year-old children were asked to match a reference stimulus (a large rectangle) to one of two choices. The first choice consisted of one rectangle that was of a different size to the reference stimulus. The second choice consisted of four rectangles, arranged close together. Taken together, these four rectangles comprised the same surface area as the reference stimulus. Children consistently chose to match the reference stimulus to the first choice - the single rectangle of a different size (Cantlon, Stafford, \& Brannon, 2010). These findings suggest that children may attend to quantity information over other information like size and surface area of objects.

To address the second presupposition, prior research also shows evidence that children of the target age possess sufficient economic understanding to allow for participation in tasks emulating purchasing. By age 3, children differentiate between money and other objects, and by age 4, many children begin naming coins (Strauss, 1952). Children at the target age also understand that money is used and is necessary in the act of purchasing goods (Schug, 1987). Children's understanding of other economic concepts is also developing, in that, by age 4 , 
children are typically aware of the effects of demand for a product on sales of the product (Siegler \& Thompson, 1998). Furthermore, 6-year-old children have been found to already possess a basic understanding of wage systems (Jahoda, 1979).

On the basis of the existence of these prerequisites, children of the target ages are wellequipped to participate in the proposed tasks. In two experiments, children between the ages of 5 and 7 years were asked to assist a fictional agent in making judgments about products' desirability and decisions about purchasing products from a shop, from a selection of scarce and abundant objects. The fictional agent was introduced in order to dissuade children from making choices based on personal preferences for toys' characteristics (as the preferences of the fictional agent were unknown), and to help focus children's attention on the relative quantities of toys. It was hypothesized that children would show a preference for scarce objects when a threat to freedom of choice was induced, through extremity of scarcity (in Experiment 1) and the presence of competition for scarce resources (in Experiment 2), compared to when these threats were not present. An age effect was also expected, with older children anticipated to show a stronger preference for scarce objects, particularly when these threats to freedom of choice were present. 


\section{Experiment 1}

Experiment 1 concerned the effect of extremity of scarcity on children's preference for scarce objects. This experiment employed a "virtual shop" paradigm, wherein children were presented with a digital representation of a toy shop, and asked to make purchasing decisions on behalf of a fictional agent. The threat to freedom of choice was induced through the manipulation of extremity of scarcity of the relatively scarce toys. In the Control condition, the ratio of abundant to scarce toys was 30:5. In the Threat condition, this ratio was 30:1.

\section{Method}

Participants. The final sample consisted of 93 typically developing children: 33 fiveyear-olds $(M=64.4$ months, range $=56.9-71.9$ months, 18 females $), 30$ six-year-olds $(M=$ 78.0 months, range $=72.7-83.5$ months, 16 females $)$, and 30 seven-year-olds $(M=89.2$ months, range $=84.1-96.1$ months, 14 females). Data from 5 children were excluded for a number of reasons, including a known developmental disability (1), experimenter error (3), or disclosure that the child had previously participated in the study at an earlier date (1). Forty-nine children participated in the Threat condition (18 five-year-olds, 15 six-year-olds, and 16 sevenyear-olds) and 44 children participated in the Control condition (15 5-year-olds, 15 6-year-olds, and 14 7-year-olds). The sample was ethnically diverse: $43.0 \%$ of participants were Asian or Pacific Islander, $31.2 \%$ were Caucasian, $3.2 \%$ were Black, $3.2 \%$ were Arab, $2.2 \%$ were Latin American, $1.1 \%$ were Aboriginal, $15.1 \%$ were identified as "other" or more than one ethnicity, and the parents of $1.1 \%$ chose not to specify.

Some of the children (23.7\% of the sample) were recruited through the Ryerson Infant and Child Database (RICD), in which case they were asked to come to the lab to participate. The majority of participants (76.3\%) were recruited at the Ontario Science Centre, and were invited 
to participate in a room adjacent to the play area where they were recruited. Preliminary analyses revealed no significant differences in response patterns between children who participated at each site.

Materials and setting. This study employed a virtual shop paradigm, presented via a PowerPoint slideshow presentation on a laptop computer. The slideshow introduced a fictional agent and set the scene of a toy shop. Each of the four trials was presented on one slide, with different novel objects being presented as toys on shelves. Novel objects were taken from the Novel Object and Unusual Name Database (Horst \& Hout, 2016). Pairs of objects were matched on familiarity as assessed by adult raters. In the Threat condition, the toys were presented in a ratio of 30:1. In the Control condition, the toys were presented in a ratio of 30:5 (see Figure 1). The study took place in a quiet room. With parental consent, a video camera was used to record responses.
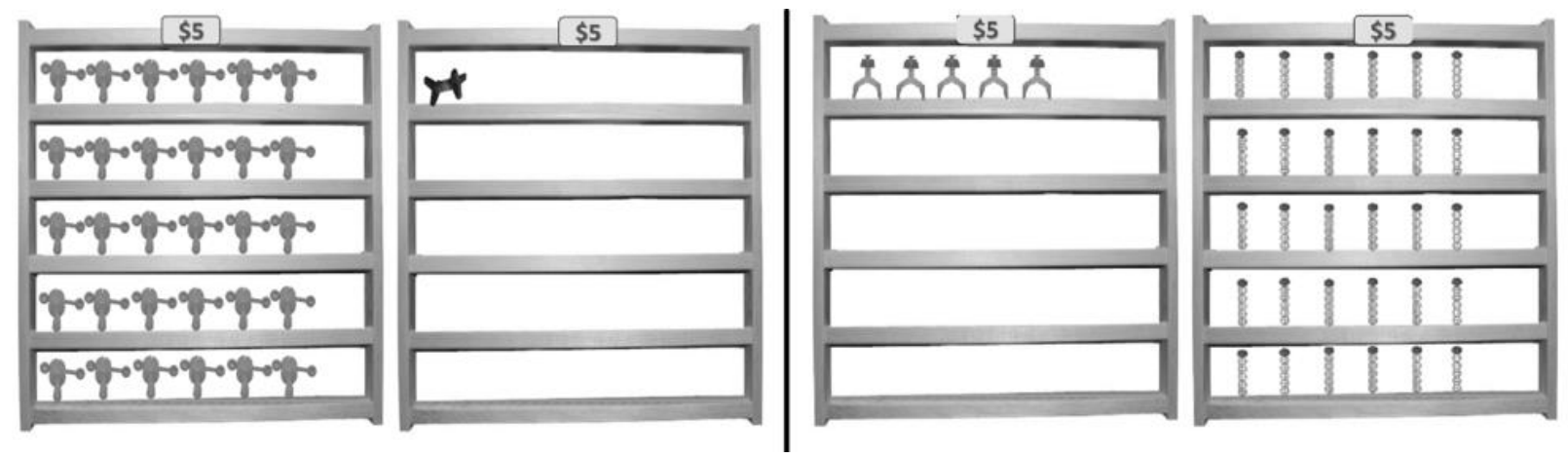

Figure 1: Sample trials from Experiment 1: Threat condition (left) and Control condition (right)

Research design. The present study employed a 2 (condition) x 3 (age group) betweensubjects design. At each age, participants were randomly assigned to either the Threat or Control condition, ensuring that there were roughly an equal number of boys and girls in each condition.

Procedure. The parent and child were directed to a waiting room where the parent completed consent and demographics forms, while the experimenter played with the child. Once 
the child was comfortable, the experimenter invited the child to participate in a computer-based task in a separate testing room.

The experimenter script (see Appendix A) introduced the child to the gender-matched fictional agent and explained that he/she had some money to spend at the toy shop, and that the child was going to help him/her decide what toys to buy. On each trial, the experimenter called attention to each toy, the prices, and the quantities. The experimenter also reminded the child that other children have already purchased some of these toys from the shop, in order to emphasize the shop setting and to imply that the relative scarcity/abundance was due to market forces. The child was then asked which toy they think is more fun (judgment task), and then which toy the agent should purchase (decision-making task). At the completion of each task type on each trial, the experimenter asked explanation questions (i.e., "Why do you think this toy is more fun? ... Why do you think [Agent name] should buy this toy? Why shouldn't he/she buy the other one?"). With parental consent, the procedure was video-recorded for reliability coding purposes.

Coding. Children's selection of scarce versus abundant objects was the dependent variable. Selection of the scarce object in a trial task was coded as "1," whereas selection of the abundant object in a trial task was coded as "0.” The experimenter coded children's responses during the procedure.

\section{Results and Discussion}

The dependent variables for these analyses were comprised of the proportion of scarce objects chosen, summed across the 4 trials. Proportions of scarce objects judged as desirable (on the judgment tasks outlined above) and the scarce objects chosen for purchase (the decisionmaking tasks outlined above) were these primary DVs. 
A repeated-measures ANOVA was conducted to examine the main effects of age group, task type, and condition on preference for scarcity, as well as the interactions between them. No significant main effects were found, nor were the interactions significant. The main effect of age group was marginally significant, $F(2,87)=2.297, p=.107$, and there was a marginally significant interaction between task type and age group, $F(2,87)=2.328, p=.104$. In general, a preference for scarcity increased with age, on both task types. Although the main effect of age was not significant, for exploratory purposes, independent samples $t$-tests were conducted to examine differences between age groups. For judgment tasks, 5-year-olds were marginally significantly less likely than 6-year-olds to prefer the scarce objects $(t(61)=-1.692, p=.096, d=$ .43) and were significantly less likely than 7-year-olds to prefer the scarce objects $(t(61)=-$ $2.688, p=.009, d=.69)$. For decision-making tasks, independent samples $t$-tests revealed that 7year-olds were marginally significantly more likely than 5-year-olds to prefer the scarce objects $(t(61)=-1.798, p=.077, d=.46)$. However, because these effects did not meet the threshold of statistical significance, the above findings are merely trends. Further analyses and discussion in this section will primarily focus on statistically significant findings, from which one can form more definitive conclusions.

One-sample $t$-tests were run to compare each age group's selection of scarce objects to selection at chance (see Figure 2). In the Threat condition, 5-year-olds were marginally significantly less likely to judge the scarce objects as more desirable than would be expected by chance, $t(17)=-1.82, p=.086$. Five-year-olds' selection of objects on decision tasks did not differ significantly from selection at chance. Similarly, 6-year-olds selection of scarce objects on both judgment and decision-making tasks did not differ significantly from selection at chance. In the Threat condition, 7-year-olds judged the scarce objects as more desirable significantly more 
often than would be expected by chance, $t(15)=2.21, p=.043, d=.55$. Additionally, their preference for scarce objects on decision-making tasks was marginally significantly above selection chance, $t(15)=1.78, p=.096$.

Bivariate correlations were run to further explore any age effects. In the Threat condition, age in months significantly predicted preference for scarcity, for judgment tasks, $r=.44, p=$ $.002, R^{2}=.20$, and for decision-making tasks, $r=.33, p=.024, R^{2}=.11$. These relationships were not significant for children in the Control condition.

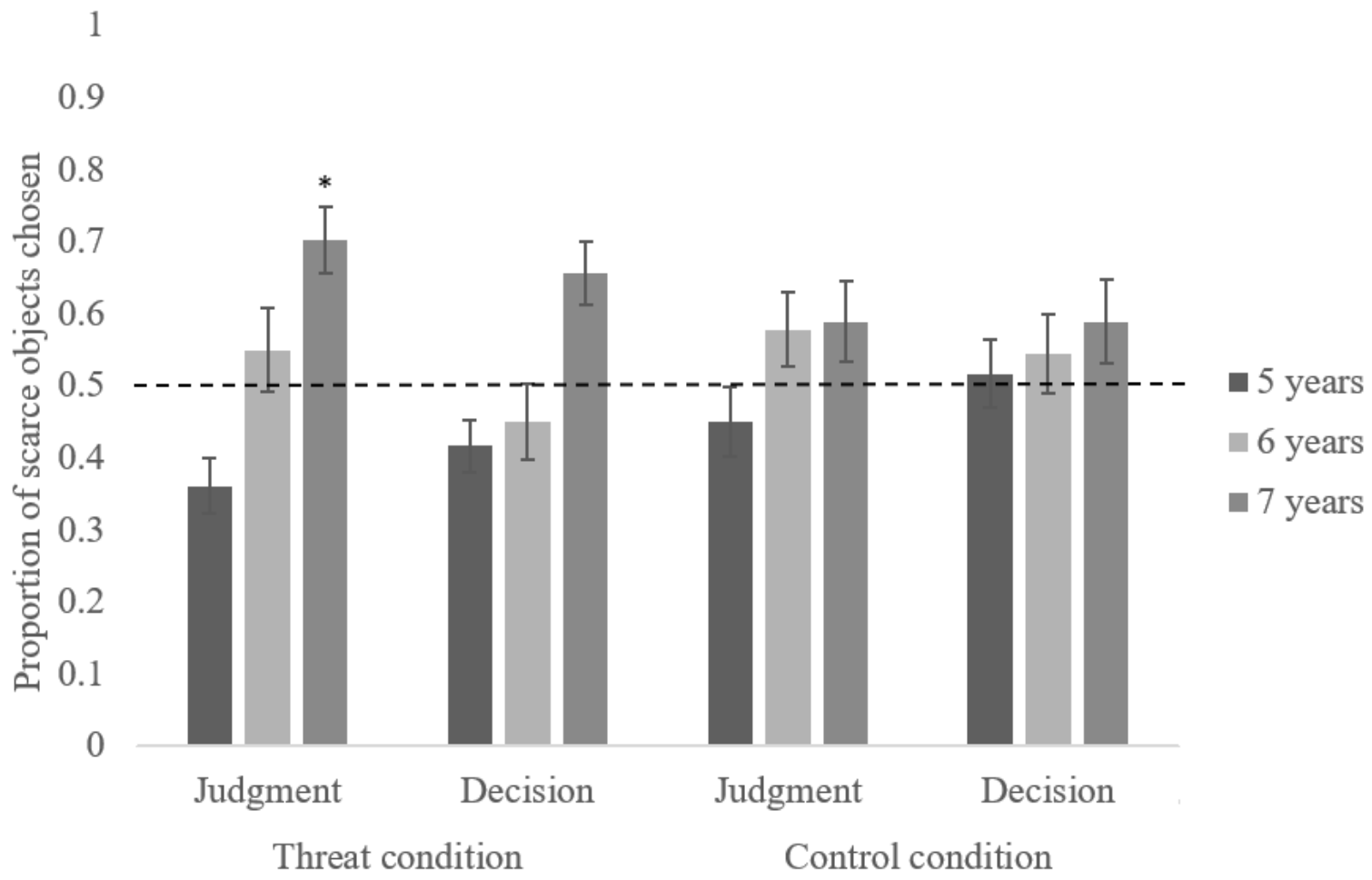

Figure 2: Proportion of scarce objects chosen. $* \mathrm{p}<.05$

Children's explanations for their judgments and decisions were also recorded, and coded into 4 categories for judgments, and 5 categories for decisions. Scarcity explanations indicate that the relative scarcity of the chosen object was the reason for its selection (e.g., "because there's only one left;" "There are less, so more kids bought it"). Abundance explanations indicate 
that the relative abundance of the chosen object was the reason for its selection (e.g., "because there are more"). Prosocial explanations include responses that indicate that the chosen object was selected in accordance with the child's desire for the agent to behave prosocially (e.g., "she should let other children have that one"). Other explanations include responses that indicate that some other characteristic of the object was the reason for its selection, including its colour, shape, or assumed function (e.g., "because red and orange are fun colours"). No response (NR) explanations encompass responses from participants who did not verbally answer the explanation question, or that indicated that they did not know why they selected the chosen object. The frequencies of these explanation types are reported in Table 1 and Table 2.

Exploratory review of children's explanations suggested developmental trends in children's reasoning about their selection of scarce and abundant objects. With age, children were more likely to cite scarcity as the reason for choosing a scarce object. This trend was particularly apparent in the Threat condition, when scarcity was extreme. With age, children also became less likely to cite abundance as the reason for choosing an abundant object. This, in combination with the trend of increasing preference for scarcity with age, further suggests that scarcity becomes more salient and more attractive with development, particularly when the relative scarcity of an object is extreme. Interestingly, the rates of prosocial justifications on decision tasks do not reveal any clear age trends in the Threat condition. In the Control condition, it does appear that older children show higher rates of prosocial justification for their choice of the abundant objects. 


\section{Table 1}

Children's explanations on judgment tasks in Experiment 1 (by condition, age group, and choice type)

\begin{tabular}{|c|c|c|c|c|c|c|}
\hline Condition & Age & Choice & Scarcity & Abundance & Other & NR \\
\hline \multirow{6}{*}{ Threat } & \multirow{2}{*}{5} & Scarce & $12(48 \%)$ & 0 & $12(48 \%)$ & $1(4 \%$ \\
\hline & & Abundant & 0 & $26(57 \%)$ & $14(30 \%)$ & $6(13 \%)$ \\
\hline & \multirow{2}{*}{6} & Scarce & $25(76 \%)$ & 0 & $6(18 \%)$ & $2(6 \%)$ \\
\hline & & Abundant & 0 & $12(44 \%)$ & $14(52 \%)$ & $1(4 \%)$ \\
\hline & \multirow{2}{*}{7} & Scarce & $34(76 \%)$ & 0 & $11(24 \%)$ & 0 \\
\hline & & Abundant & 0 & $7(37 \%)$ & $11(58 \%)$ & $1(5 \%)$ \\
\hline \multirow{6}{*}{ Control } & \multirow{2}{*}{5} & Scarce & $10(37 \%)$ & 0 & $15(56 \%)$ & $2(7 \%)$ \\
\hline & & Abundant & 0 & $13(39 \%)$ & $16(49 \%)$ & $4(12 \%)$ \\
\hline & \multirow{2}{*}{6} & Scarce & $17(50 \%)$ & 0 & $14(41 \%)$ & $3(9 \%)$ \\
\hline & & Abundant & 0 & $9(41 \%)$ & $9(41 \%)$ & $4(18 \%)$ \\
\hline & \multirow{2}{*}{7} & Scarce & $24(73 \%)$ & 0 & $9(27 \%)$ & 0 \\
\hline & & Abundant & 0 & $5(22 \%)$ & $17(74 \%)$ & $1(4 \%)$ \\
\hline
\end{tabular}

\section{Table 2}

Children's explanations on decision tasks in Experiment 1 (by condition, age group, and choice type)

Condition Age Choice Scarcity Abundance Prosocial Other NR

\begin{tabular}{|c|c|c|c|c|c|c|c|}
\hline \multirow{6}{*}{ Threat } & \multirow{2}{*}{5} & Scarce & $9(30 \%)$ & 0 & 0 & $18(60 \%)$ & $3(10 \%)$ \\
\hline & & Abundant & 0 & $16(38 \%)$ & $6(14 \%)$ & $14(34 \%)$ & $6(14 \%)$ \\
\hline & \multirow{2}{*}{6} & Scarce & $17(65 \%)$ & 0 & 0 & $8(31 \%)$ & $1(4 \%)$ \\
\hline & & Abundant & 0 & $6(18 \%)$ & $12(36 \%)$ & $15(46 \%)$ & 0 \\
\hline & \multirow{2}{*}{7} & Scarce & $29(71 \%)$ & 0 & 0 & $12(29 \%)$ & 0 \\
\hline & & Abundant & 0 & $4(18 \%)$ & $1(5 \%)$ & $17(77 \%)$ & 0 \\
\hline \multirow{6}{*}{ Control } & \multirow{2}{*}{5} & Scarce & $4(13 \%)$ & 0 & $2(7 \%)$ & $23(74 \%)$ & $2(6 \%)$ \\
\hline & & Abundant & 0 & $14(48 \%)$ & $2(7 \%)$ & $9(31 \%)$ & $4(14 \%)$ \\
\hline & \multirow{2}{*}{6} & Scarce & $16(50 \%)$ & 0 & 0 & $16(50 \%)$ & 0 \\
\hline & & Abundant & 0 & $3(11 \%)$ & 0 & $20(74 \%)$ & $4(15 \%)$ \\
\hline & \multirow{2}{*}{7} & Scarce & $22(67 \%)$ & 0 & 0 & $11(33 \%)$ & 0 \\
\hline & & Abundant & 0 & $4(17 \%)$ & $5(22 \%)$ & $14(61 \%)$ & 0 \\
\hline
\end{tabular}

To summarize, when the scarce versus abundant objects were presented in a ratio of 30:5, 5- to 7-year-olds did not show a significant preference for scarcity. This finding is consistent 
with recent work showing that a robust preference for scarcity (specifically, when resources are offered in a ratio of 30:4) does not emerge until children are 8 years of age (Ma, in preparation). However, in cases of extreme scarcity (30:1), 7-year-olds demonstrated a significant preference for scarce objects when judging an object's desirability. This preference for extreme scarcity increased with age, suggesting that scarcity became more salient and attractive when threat to freedom of choice was induced.

One interesting finding concerns the disparity between the proportion of scarce objects selected on judgment and decision-making tasks seen among 7-year-olds. Prosocial behaviour may prevent these children from selecting the last remaining object for purchase. However, as reported above, the explanations given by the participants did not indicate strong prosocial motivations. The lack of immediately-present others in the virtual shop may have inhibited children from mentioning the effect of selecting the last of an object on others, even if this was something they were considering. 


\section{Experiment 2}

Experiment 2 aimed to further elucidate the role of perceived threat to freedom of choice in children's development of preference for scarce resources, by inducing this perceived threat through the presence of competition. This experiment also utilized a virtual shop paradigm. As in Experiment 1, children were asked to choose between highly abundant toys and relatively scarce toys on each trial. In the Threat condition, the fictional agent was accompanied by competition in the form of peers who were also purchasing toys from the shop.

\section{Method}

Participants. The final sample consisted of 92 typically developing children: 32 fiveyear-olds $(M=64.5$ months, range $=57.4-71.5$ months, 18 females $), 30$ six-year-olds $(M=$ 78.2 months, range $=72.1-83.4$ months, 17 females $)$, and 30 seven-year-olds $(M=88.7$ months, range $=83.9-95.1$ months, 13 females). Data from 11 children was excluded for a number of reasons, including a known developmental disability (1), family interference during the procedure (1), ineligible age (2), difficulty with instructions (1), unwillingness to complete the procedure (1), or disclosure that the child had previously participated in the study at an earlier date (5). Forty-six children participated in the Threat condition (15 five-year-olds, 15 sixyear-olds, and 16 seven-year-olds) and 46 children participated in the Control condition (17 fiveyear-olds, 15 six-year-olds, and 14 seven-year-olds). As in Experiment 1, the sample was ethnically diverse: $39.1 \%$ of participants were Asian or Pacific Islander, $34.8 \%$ were Caucasian, $1.1 \%$ were Black, $1.1 \%$ were Arab, $1.1 \%$ were Latin American, $15.2 \%$ were identified as "other" or more than one ethnicity, and the parents of $7.6 \%$ chose not to specify.

Participants were recruited in the same manner as in Experiment 1; 8.7\% were recruited through the RICD and participated in the lab, and $91.3 \%$ were recruited and tested at the Ontario 
Science Centre. As in Experiment 1, preliminary analyses revealed no meaningful differences in response patterns between children who participated at each site.

Materials, setting, and research design. The materials, setting, and research design were the same as in Experiment 1.

Procedure. Parental consent, demographics, and the introduction phase were conducted in the same manner as in Experiment 1. As in Experiment 1, the fictional agent was introduced and each of the four trials was presented on one PowerPoint slide, with different novel objects being presented as toys on shelves in a toy shop. In Experiment 2, however, the toys were presented in a ratio of 30:2 across both the Threat and Control conditions. In the Threat condition, two other characters (the competition) were introduced as other children who were buying toys as well (see Figure 3). No competition was present in the Control condition. On each trial, the experimenter called attention to each toy, the prices, and the quantities. The experimenter also reminded the child that other children have already purchased some of these toys from the shop. In the Threat condition, the experimenter also reminded the child that there are two other agents who are buying toys as well. The child was then asked which toy they think is more fun (the judgment task), and which toy the agent should purchase (the decision-making task). At the completion of each task type on each trial, the experimenter asked the same explanation questions as in Experiment 1. The experimenter script can be found in Appendix A. With parental consent, the procedure was video-recorded for reliability coding purposes. 

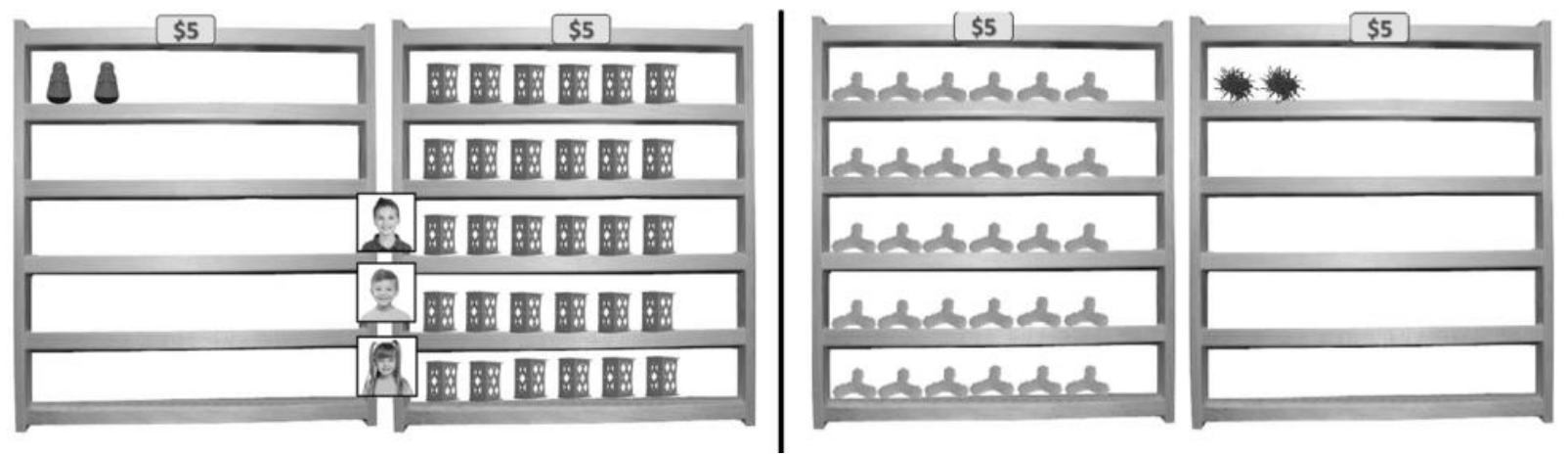

Figure 3: Sample trials from Experiment 2. Trial in the Threat condition (left) and trial in the Control condition (right).

Coding. Children's selection of scarce versus abundant objects was coded in the same manner as in Experiment 1. The experimenter coded children's responses during the procedure.

\section{Results and Discussion}

A repeated-measures ANOVA was conducted to examine the main effects of condition, task type, and age on preference for scarcity, as well as the interaction between them. There was no significant main effect of task type or condition, nor was there a significant interaction between condition and age group. However, there was a significant main effect of age group, $F(2,86)=10.359, p<.001, \eta^{2}=.194$. Post-hoc LSD tests revealed that, on both judgment and decision-making tasks, 5-year-olds were significantly less likely to choose the scarce objects than 6-year-olds $(p=.001$ and $p=.025)$ or 7-year-olds $(p<.001$ and $p=.004)$.

One-sample $t$-tests were run to compare each age group's selection of scarce objects to selection at chance. In the Threat condition, 5-year-olds judged the scarce objects as desirable significantly less often than would be expected by chance, $t(14)=-3.17, p=.007, d=.82$, and also selected them for purchase on decision-making tasks significantly less often than would be expected by chance, $t(14)=-2.98, p=.010, d=.76$. Five-year-olds' judgments and decisions in the Control condition did not vary significantly from selection at chance. 
In the Threat condition, 6-year-olds judged the scarce objects as desirable significantly more often than would be expected by chance, $t(14)=2.69, p=.017, d=.70$. This was not true on decision-making tasks. Six-year-olds' judgments and decisions in the Control condition did not vary significantly from selection at chance.

As for the 7-year-olds, in the Threat condition they judged the scarce objects as desirable significantly more often than would be expected at chance, $t(15)=4.07, p=.001, d=1.02$. This was not true on decision-making tasks. However, in the Control condition, 7-year-olds judged the scarce objects as desirable, $t(13)=2.28, p=.040, d=.61$, and selected the scarce objects for purchase, $t(13)=2.60, p=.022, d=.70$, significantly more often than would be expected by chance. Figure 4 displays the proportion of scarce objects chosen in Experiment 2.

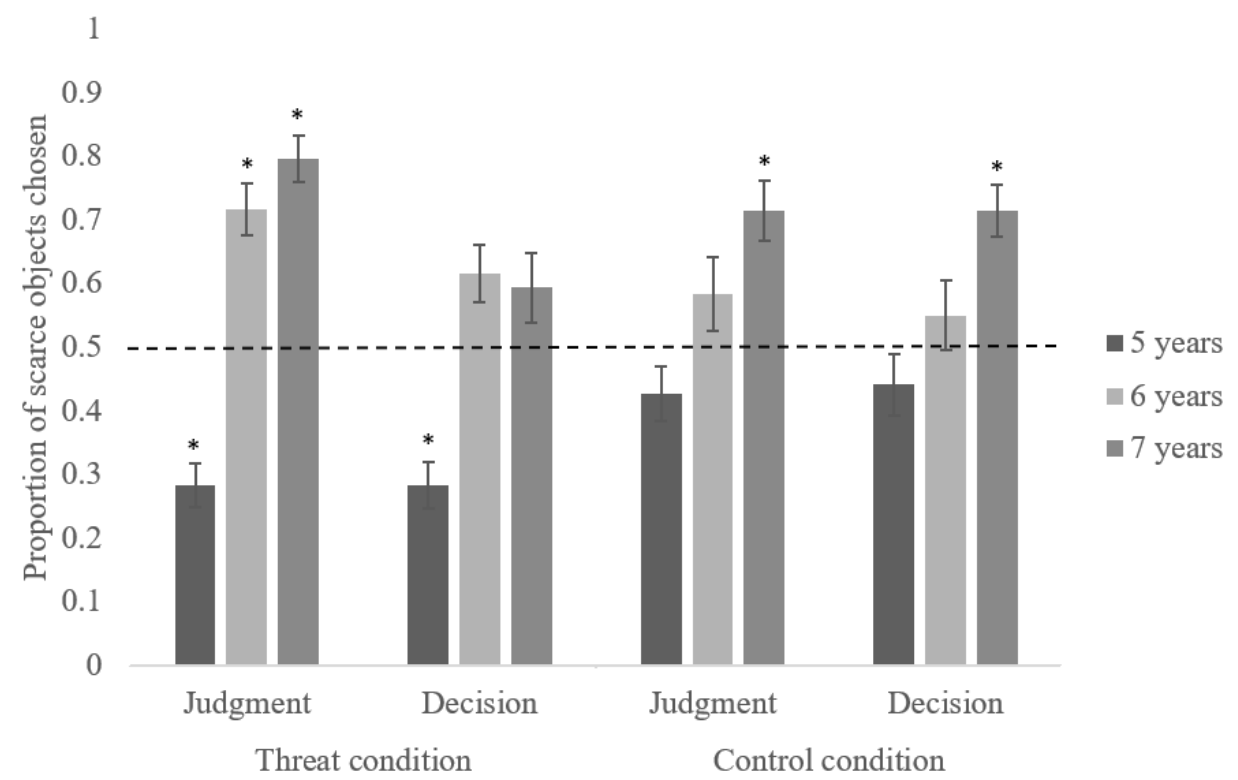

Figure 4: Proportion of scarce objects chosen. $* p<.05$

Bivariate correlations were run to further explore any age effects. In the Threat condition, age in months significantly predicts preference for scarcity, for judgment tasks, $r=.61, p<.001$, $R^{2}=.38$, and for decision-making tasks, $r=.33, p=.024, R^{2}=.11$. Similarly, in the Control 
condition, age in months significantly predicts preference for scarcity, for judgment tasks, $r=$ $.40, p=.006, R^{2}=.16$, and for decision-making tasks, $r=.32, p=.032, R^{2}=.10$.

Children's explanations for their judgments and decisions were also recorded, and coded into the same categories as in Experiment 1 (4 for judgments and 5 for decisions). The frequencies of these explanation types are reported in Table 3 and Table 4. As in Experiment 1, the likelihood of a child citing scarcity as their motivation for selecting a scarce object increases with age, and the likelihood of citing abundance for abundant choices decreases slightly with age. Again, scarcity appears to be increasingly salient and attractive as children age. The threat to freedom of choice, as represented by the presence of competition in the Threat condition, does not appear to impact this trend. Also akin to trends in Experiment 1, rates of prosocial responses do not demonstrate any clear age trend in Experiment 2.

\section{Table 3}

Children's explanations on judgment tasks in Experiment 2 (by condition, age group, and choice type)

\begin{tabular}{|c|c|c|c|c|c|c|}
\hline Condition & Age & Choice & Scarcity & Abundance & Other & NR \\
\hline \multirow{6}{*}{ Threat } & \multirow{2}{*}{5} & Scarce & $3(18 \%)$ & 0 & $13(76 \%)$ & $1(6 \%)$ \\
\hline & & Abundant & 0 & $16(37 \%)$ & $24(56 \%)$ & $3(7 \%)$ \\
\hline & \multirow{2}{*}{6} & Scarce & $27(63 \%)$ & 0 & $12(28 \%)$ & $4(9 \%)$ \\
\hline & & Abundant & 0 & $3(18 \%)$ & $11(64 \%)$ & $3(18 \%)$ \\
\hline & \multirow{2}{*}{7} & Scarce & $38(78 \%)$ & 0 & $10(20 \%)$ & $1(2 \%)$ \\
\hline & & Abundant & 0 & $5(33 \%)$ & $7(47 \%)$ & $3(20 \%)$ \\
\hline \multirow{6}{*}{ Control } & \multirow{2}{*}{5} & Scarce & $16(55 \%)$ & 0 & $11(38 \%)$ & $2(7 \%)$ \\
\hline & & Abundant & 0 & $21(54 \%)$ & $15(38 \%)$ & $3(8 \%)$ \\
\hline & \multirow{2}{*}{6} & Scarce & $22(63 \%)$ & 0 & $12(34 \%)$ & $1(3 \%)$ \\
\hline & & Abundant & 0 & $8(32 \%)$ & $13(52 \%)$ & $4(16 \%)$ \\
\hline & \multirow{2}{*}{7} & Scarce & $31(78 \%)$ & 0 & $9(22 \%)$ & 0 \\
\hline & & Abundant & 0 & $7(44 \%)$ & $9(56 \%)$ & 0 \\
\hline
\end{tabular}




\section{Table 4}

Children's explanations on decision tasks in Experiment 2 (by condition, age group, and choice type)

\begin{tabular}{|c|c|c|c|c|c|c|c|}
\hline Condition & Age & Choice & Scarcity & Abundance & Prosocial & Other & NR \\
\hline \multirow{6}{*}{ Threat } & \multirow{2}{*}{5} & Scarce & $2(12 \%)$ & 0 & 0 & $13(76 \%)$ & $2(12 \%)$ \\
\hline & & Abundant & 0 & $16(37 \%)$ & $11(26 \%)$ & $15(35 \%)$ & $1(2 \%)$ \\
\hline & \multirow{2}{*}{6} & Scarce & $23(62 \%)$ & 0 & 0 & $13(35 \%)$ & $1(3 \%)$ \\
\hline & & Abundant & 0 & $4(17 \%)$ & $10(44 \%)$ & $7(30 \%)$ & $2(9 \%)$ \\
\hline & \multirow{2}{*}{7} & Scarce & $33(87 \%)$ & 0 & 0 & $5(13 \%)$ & 0 \\
\hline & & Abundant & 0 & $7(26 \%)$ & $9(35 \%)$ & $9(35 \%)$ & $1(4 \%)$ \\
\hline \multirow{6}{*}{ Control } & \multirow{2}{*}{5} & Scarce & $16(53 \%)$ & 0 & 0 & $11(37 \%)$ & $3(10 \%)$ \\
\hline & & Abundant & 0 & $14(37 \%)$ & $9(23 \%)$ & $14(37 \%)$ & $1(3 \%)$ \\
\hline & \multirow{2}{*}{6} & Scarce & $20(61 \%)$ & 0 & $1(3 \%)$ & $11(33 \%)$ & $1(3 \%)$ \\
\hline & & Abundant & 0 & $8(30 \%)$ & $10(37 \%)$ & $9(33 \%)$ & 0 \\
\hline & \multirow{2}{*}{7} & Scarce & $30(75 \%)$ & 0 & 0 & $10(25 \%)$ & 0 \\
\hline & & Abundant & 0 & $4(25 \%)$ & $5(31 \%)$ & $7(44 \%)$ & 0 \\
\hline
\end{tabular}

Experiment 2 serves, in part, as a conceptual replication of Experiment 1. The Threat condition of Experiment 1 (objects in a ratio of 30:1) is functionally very similar to the Control condition of Experiment 2 (objects in a ratio of 30:2). For exploratory purposes, informal comparisons were made between patterns of responses in these conditions. As depicted in Figure 2 and Figure 4, children's patterns of responses in these two conditions were very similar, particularly for 7-year-olds. This provides further evidence that, in cases of relatively extreme scarcity, 7-year-olds begin to display the scarcity effect, perhaps due to the perceived threat to freedom of choice induced by this extreme scarcity.

In the Threat condition, 7-year-olds show a strong preference for the scarce objects on the judgment tasks, as they do on both task types in the Control condition. Similarly, 6-year-olds show a robust preference for scarcity on judgment tasks in the Threat condition. However, 6- and 7-year-olds do not show this same preference for the scarce objects on decision-making tasks in the Threat condition. The only difference between the two conditions is the presence of 
competition in the Threat condition. As such, it is reasonable to assume that the presence of competition is dissuading these children from selecting the scarce objects for the agent to purchase. It is possible that this is due to a tendency toward prosocial behaviour. This is supported by the number of explanation responses given that indicate prosocial motives for children's decisions, reported above in Table 4. This prosociality explanation is also supported by the literature on the development of prosocial behaviour. Research has suggested that prosocial behaviour develops early in life, and that many children display sharing behaviours by the time they are 2 years of age (Hay, 1979) and that other prosocial behaviours similarly develop early in life (e.g., helping develops as early as 14 months of age, Warneken \& Tomasello, 2007; comforting behaviours may begin to develop in the first year of life, Paulus \& Moore, 2012). As such, it is reasonable to expect that children of the target age range have developed prosocial behaviours and may have prosocial motivations behind their actions.

Moreover, preschoolers have been shown to use actors' moral behaviour to allocate scarce resources, punishing immoral actions with fewer resources and rewarding prosocial behaviours with more (Kenward \& Dahl, 2011). However, because the moral character of the competition in Experiment 2 was unknown, it is possible that children had few cues to make decisions about who should have the scarce toys left in the shop, and so, did not generally show patterns in their decisions. Interestingly, 5-year-olds showed a robust preference for the abundant objects on both judgment and decision tasks in the Threat condition. This may be because of a tendency for young children to prefer abundant objects, and because there is no obvious prosocial reason to avoid taking an abundant toy, act in accordance with their judgments. That is to say, 5-year-olds' preference for abundance on decision tasks may reflect a genuine preference for abundant objects. This is supported by the below-chance trend in the Control condition of 
Experiment 2, and the same below-chance trend seen in the results of Experiment 1. This is also supported by the trend for 5-year-olds to cite abundance as their motivation for selecting an abundant object more often than they cite prosociality. This is also consistent with previous findings that young children may have a preference for large numbers over smaller ones (Towse, Loetscher, \& Brugger, 2014), which may have prompted 5-year-olds to indicate a preference for the more abundant toys. 


\section{General Discussion}

The present research provides evidence to suggest that the scarcity effect can be induced in young children who would not otherwise display a preference for scarcity, through activation of perceived threat to freedom of choice. In general, a preference for scarcity increases with age, particularly when threat to freedom of choice is induced. The manipulations of Experiment 2 appear to be more successful in inducing a preference for scarcity than Experiment 1 . This is perhaps due to the fact that, while Experiment 1 presented objects in a relatively extreme ratio of abundance/scarcity, Experiment 2 presented the objects in a ratio nearly as extreme, and also introduced the presence of competition.

The present research provides support for reactance theory (Brehm, 1966), with some children reacting to threat to freedom of choice, as it pertains to possessing scarce objects, with a strong preference for these objects. This research helps to contextualize reactance theory within developmental psychology, providing evidence for the idea that children, like adults, are subject to psychological reactance and do tend to behave in ways to restore feelings of freedom when that freedom is threatened. Similar to Brehm and Weinraub (1977) demonstrating that young children desire objects to which their access is physically impeded, it appears that threat to access by way of extreme scarcity and/or the presence of competition also increases desire for objects - albeit, later in development perhaps than physical barriers.

As demonstrated by Ma (in preparation), by age 8 , children show a strong preference for scarcity when objects are presented in a ratio of 30:4. It may be the case that before age 8 , children are not sensitive to the threat to freedom of choice represented by scarce objects presented in that ratio, and in the absence of immediate competition for scarce resources. By increasing the extremity of scarcity and introducing immediately present competition for scarce 
resources, the present study may have brought the threat to freedom of choice to a higher level to which younger children (particularly 7-year-olds) are sensitive. The findings from both experiments in this study provide converging evidence that scarcity becomes more salient and attractive as children age, based on the increasing proportion of scarce objects chosen and the increasing frequency with which children cite scarcity as motivation for selection of a scarce object. Because this trend appears to be particularly strong in the Threat condition of Experiment 1, increasing the extremity of scarcity may be responsible for bringing the threat to freedom of choice to a level to which 7-year-olds are sensitive.

These results may also be accounted for by children's use of heuristics. It is possible that children, upon observing the relative scarcity of a toy, and after being shown and told that the toy's scarcity was due to many other children having purchased it, merely inferred the toy's popularity, and so, its higher desirability. This is to say, perhaps the developmental trend of the increasing preference for scarcity was not due to an increasing sensitivity to the threat to freedom of choice represented by extreme scarcity and/or competition, but merely an increased likelihood of inferring and conforming to the preference of the majority. This interpretation is supported by research showing that children as young as 3 years of age display heuristic thinking (Tkhorzhevskii, 1972). Further research is needed to explore the mechanisms underlying children's preference for scarcity, and to parse apart the respective roles of relative scarcity itself and social demand for a resource in children's preference for scarce resources.

As noted previously, prosocial behaviours - including sharing behaviours - have been found to develop over the first two years of life (Paulus \& Moore, 2012). Research has suggested that, by age 2, the majority of children show sharing behaviours, sharing their toys with others during play (Hay, 1979). Other research has found that some preschoolers are willing to share 
desirable resources, even when it comes at a cost to themselves (Thompson, Barresi, \& Moore, 1997).

From a developmental standpoint, the children who participated in the present research were all at an age where sharing and other prosocial behaviours are expected to be commonplace, according to the above research. In Experiment 1, the tendency for 7-year-olds to judge the scarce objects as more desirable, but not show a preference for them on decision tasks may be due to prosocial intent. Likewise, in Experiment 2, the tendency for 6- and 7-year-olds to judge scarce objects as more desirable, but to not be as likely to select them for purchase in the presence of peers, can reasonably be attributed to prosocial behaviour. That is to say, a preference for extreme scarcity, and for scarcity in the immediate presence of competition, may develop by age 6 to 7 years, but this preference may not manifest on tasks where children perceive there to be a prosocial option for their behaviour. This is supported by the observed trend for some children to cite prosocial intent for their reason to select an abundant object for purchase. This disparity between children's judgments and the decisions they make underscores the importance of measuring both of these constructs.

Literature on children's understanding of fairness and preference for equity indicates that, by age 7 or 8 years, children show a preference for equitable distribution of resources (Fehr, Bernhard, \& Rockenbach, 2008). Additional research has indicated that only by age 7 or 8 years do children endorse unequal allocation of resources in order to fix a pre-existing inequality, and only at this age did they reject distributions that were equal but did not address pre-existing inequalities (Rizzo \& Killen, 2016). Relatedly, 7- and 8-year-olds have been found to be significantly more likely than 4- to 6-year-olds to create a situation of inequitable distribution of resources that disadvantages themselves (Shaw, Choshen-Hillel, \& Caruso, 2016). 
Other research has found that, in general, altruism in the context of resource allocation increases with age throughout childhood. In an investigation of 3- to 6-year-olds' behaviour in a Dictator Game, children become significantly more likely to share resources with age (Blake \& Rand, 2010). Moreover, a study examining the behaviour of Chinese children aged 3 to 9 years in mini-Dictator games revealed that there was a small to moderate effect of age on altruism towards strangers, and a moderate to large effect of age on altruism towards friends (Yu, Zhu, \& Leslie, 2016). These findings further support the idea that the disparity between children's performance on judgment and decision tasks can reasonably be attributed to older children's prosocial intent and increasing preference for equitable allocation of resources.

Research into the scarcity effect in adults has also revealed that adults sometimes display prosocial tendencies when making decisions about scarce resources. In one study, adults were given the opportunity to select a cookbook from a selection of three books, which varied in relative quantity and, if scarce, the reasons for their scarcity. It was found that books that were scarce due to market conditions (i.e., low supply and/or high demand) were selected more often than books that were scarce due to accidental causes, or books that were freely and abundantly available. However, when participants were told that they were the first of many participants to select a book to take home, this effect disappeared (Verhallen \& Robben, 1994). This suggests that adults are aware of the effect of their decisions about scarce resources on others, and can act accordingly to avoid disadvantaging others. The authors note that "sensitivity to social pressure moderates the effect of limited availability on overt choice" (Verhallen \& Robben, 1994, p. 327). It is therefore possible that the pattern of results displayed in the present study, with some children showing a preference for scarce objects but hesitation to select them for purchase, are reflective of this type of prosocial, sharing behaviour. This suggests that prosocial behaviours 
relating to decisions about scarce resources may develop relatively early in life and endure into adulthood.

The present research examined the malleability of young children's preference for scarcity, and explored the possibility of inducing the scarcity effect in young children by activating perceived threat to freedom of choice. Future research may continue to explore the mechanisms underlying the development of the scarcity effect, including the impact of different causes of scarcity, the role of an object's inherent desirability in children's preference for scarcity, and whether preference for scarcity can be induced through training by demonstrating covariation of attributes (i.e., scarcity and desirability).

Furthermore, as noted previously, research suggests that adults from different cultures differentially display preferences for scarcity (Jung \& Kellaris, 2004). Moreover, previous research (Rao \& Stewart, 1999) suggests that there exist cultural differences in young children's sharing behaviours. Future research may aim to systematically assess cultural differences in children's preference for scarcity and allocation of scarce resources, particularly when choosing for others (as in the case of the virtual shop, where decisions are made on behalf of the fictional agent, and these decisions have an impact on the competition present in the Threat condition of Experiment 2).

The present study has some limitations. First, the virtual shop design does not necessarily reflect how children reason about scarcity in real-world situations. Because the shop was fictional and participants were selecting fictional toys for fictional agents, the present study is not necessarily ecologically valid. Other aspects of the study interfere with ecological validity as well, including the fact that the experimental script called explicit attention to the relative 
scarcity and abundance of toys - a factor that is not necessarily present in real-world shopping scenarios.

While preference for scarcity in adulthood has been studied relatively at length, the same phenomenon in children has received considerably less research attention. As such, the present research adds significantly to the literature on the influence of scarcity on judgment and decision making, particularly in the developmental context. This research will lead to a better understanding of children's use of statistical information. Specifically, this research helps elucidate the early development of preference for scarcity, including early social and statistical contributors to preference for scarce resources. This may help us to understand the mechanisms underlying preference for scarcity observed at any age. Furthermore, this research also helps explain some of the social and statistical factors influencing children's real-world economic and purchasing decisions. 


\section{Appendix A}

\section{Experiment 1 Script}

Introduction Phase:

$\underline{\text { Slide } 1}$

Are you ready to play the toy shop game?

\section{Slide 2}

This is Binky/Betsy. He/She just earned \$20 from walking his/her neighbor's dog. Binky/Betsy wants to spend the money buying some toys.

\section{$\underline{\text { Slide } 3}$}

This is the toy shop where Binky/Betsy is going to buy his/her toys.

\section{$\underline{\text { Slide } 4}$}

Lots of kids like to buy toys here. Can you help Binky/Betsy choose some toys?

\section{$\underline{\text { Test Phase: }}$}

\section{Trials 1-4:}

Here are two kinds of toys. Each toy costs five dollars.

This is how the shelves looked this morning. Other kids have bought some of these toys since then - look! (clicks to fade toys to a ratio of 30:5 / 30:1)

There are lots left of this toy (points to abundant toy) and [a few] / [only 1] left of this toy. (points to scarce toy)

Which toy do you think is more fun? This one (points to left) or this one? (points to right) Why?

Binky/Betsy needs help picking a toy. Which one do you think he/she should get? This one (points to left) or this one? (points to right) Why? Why didn't you think he/she should buy this one? (points to other toy)

\section{Closing:}

Great job! Thanks for helping Binky/Betsy pick his/her new toys! He/She has just paid $\$ 20$ and is putting the new toys in a bag to take home!

Thanks for all your help! 


\section{Experiment 2 Script}

Introduction Phase:

$\underline{\text { Slide } 1}$

Are you ready to play the toy shop game?

Slide 2

This is Binky/Betsy. He/She just earned \$20 from walking his/her neighbor's dog.

Binky/Betsy wants to spend the money buying some toys.

\section{$\underline{\text { Slide } 3}$}

This is the toy shop where Binky/Betsy is going to buy his/her toys.

$\underline{\text { Slide } 4}$

Lots of kids like to buy toys here. Can you help Binky/Betsy choose some toys?

\section{Test Phase:}

Trials 1-4:

Here are two kinds of toys. Each toy costs five dollars.

This is how the shelves looked this morning. Other kids have bought some of these toys since then - look! (clicks to fade toys to a ratio of 30:2)

There are lots left of this toy (points to abundant toy) and only two left of this toy. (points to scarce toy)

Which toy do you think is more fun? This one (points to left) or this one? (points to right) Why?

\section{[In EXPERIMENTAL CONDITION only]}

(clicks to reveal Binky/Betsy) Binky/Betsy is going to pick a toy. (clicks to reveal other children) There are also two other kids in the shop who are going to pick from these toys too.

\section{[ALL CONDITIONS]}

Binky/Betsy needs help picking a toy. Which one do you think he/she should get? This one (points to left) or this one? (points to right) Why? Why didn't you think he/she should buy this one? (points to other toy) 


\section{Closing:}

Great job! Thanks for helping Binky/Betsy pick his/her new toys! He/She has just paid $\$ 20$ and is putting the new toys in a bag to take home!

Thanks for all your help! 


\section{References}

Blake, P. R., \& Rand, D. G. (2010). Currency value moderates equity preference among young children. Evolution and Human Behavior, 31(3), 210-218. doi:http://dx.doi.org/10.1016/j.evolhumbehav.2009.06.012

Brannon, L. A., \& Brock, T. C. (2001). Scarcity claims elicit extreme responding to persuasive messages: Role of cognitive elaboration. Personality and Social Psychology Bulletin, 27(3), 365-375. doi:http://dx.doi.org/10.1177/0146167201273010

Brehm, J. W. (1966). A theory of psychological reactance. Academic Press, Oxford.

Brehm, J. W., Stires, L. K., Sensenig, J., \& Shaban, J. (1966). The attractiveness of an eliminated choice alternative. Journal of Experimental Social Psychology, 2(3), 301-313. doi:http://dx.doi.org/10.1016/0022-1031(66)90086-2

Brehm, S. S., \& Weinraub, M. (1977). Physical barriers and psychological reactance: 2-yr-olds' responses to threats to freedom. Journal of Personality and Social Psychology, 35(11), 830-836. doi:http://dx.doi.org/10.1037/0022-3514.35.11.830

Brock, T. C. (1968). Implications of commodity theory for value change. In A. G. Greenwald, T. C. Brock, \& T. M. Ostrom (Eds.), Psychological foundations of attitudes (pp. 243-275). New York: Academic Press.

Brock, T. C., \& Brannon, L. A. (1992). Liberalization of commodity theory. Basic and Applied Social Psychology, 13(1), 135-144. doi:http://dx.doi.org/10.1207/s15324834basp1301_1

Cantlon, J. F., Safford, K. E., \& Brannon, E. M. (2010). Spontaneous analog number representations in 3-year-old children. Developmental Science, 13(2), 289-297. doi:http://dx.doi.org/10.1111/j.1467-7687.2009.00887.x 
Ditto, P. H., \& Jemmott, J. B. (1989). From rarity to evaluative extremity: Effects of prevalence information on evaluations of positive and negative characteristics. Journal of Personality and Social Psychology, 57(1), 16-26. doi:http://dx.doi.org/10.1037/0022-3514.57.1.16

Egan, L. C., Bloom, P., \& Santos, L. R. (2010). Choice-induced preferences in the absence of choice: Evidence from a blind two choice paradigm with young children and capuchin monkeys. Journal of Experimental Social Psychology, 46(1), 204-207. doi:http://dx.doi.org/10.1016/j.jesp.2009.08.014

Erez, N., Weiss, P. L., Kizony, R., \& Rand, D. (2013). Comparing performance within a virtual supermarket of children with traumatic brain injury to typically developing children: A pilot study. OTJR: Occupation, Participation and Health, 33(4), 218-227. doi:http://dx.doi.org/10.3928/15394492-20130912-04

Fehr, E., Bernhard, H., \& Rockenbach, B. (2008) Egalitarianism in young children. Nature, 454(7208), 1079-1083. doi: 10.1038/nature07155

Feigenson, L., Dehaene, S., \& Spelke, E. (2004). Core systems of number. Trends in Cognitive Sciences, 8(7), 307-314. doi:http://dx.doi.org/10.1016/j.tics.2004.05.002

Fromkin, H. L., \& Brock, T. C. (1971). A commodity theory analysis of persuasion. Representative Research in Social Psychology, 2(1), 47-57. Retrieved from http://ezproxy.lib.ryerson.ca/login?url=http://search.proquest.com/docview/615756116?acc ountid=13631

Fromkin, H. L., \& Snyder, C. R. (1980). The search for uniqueness and valuation of scarcity: A neglected dimension of value in exchange theory. In K. Gergen, M. S. Greenberg, \& R. H. Willis (Eds.), Social exchange: Advances in theory and research (pp. 57-75). New York: Plenum. 
Gierl, H., \& Huettl, V. (2010). Are scarce products always more attractive? The interaction of different types of scarcity signals with products' suitability for conspicuous consumption. International Journal of Research in Marketing, 27, 225-235. doi:http://dx.doi.org/10.1016/j.ijresmar.2010.02.002

Hay, D. F. (1979). Cooperative interactions and sharing between very young children and their parents. Developmental Psychology, 15, 647-653. doi:http://dx.doi.org/10.1037/00121649.15.6.647

Horst, J. S., \& Hout, M. C. (2016). The novel object and unusual name (NOUN) database: A collection of novel images for use in experimental research. Behavior Research Methods, 48(4), 1393-1409. doi:http://dx.doi.org.ezproxy.lib.ryerson.ca/10.3758/s13428-015-0647-3

Jahoda, G. (1979). The construction of economic reality by some Glaswegian children. European Journal of Social Psychology, 9(2), 115-127.

doi:http://dx.doi.org/10.1002/ejsp.2420090202

Jordan, N. C., Kaplan, D., Ramineni, C., \& Locuniak, M. N. (2009). Early math matters: Kindergarten number competence and later mathematics outcomes. Developmental Psychology, 45(3), 850-867. doi:http://dx.doi.org/10.1037/a0014939

Jung, J. M., \& Kellaris, J. J. (2004). Cross-national differences in proneness to scarcity effects: The moderating roles of familiarity, uncertainty avoidance, and need for cognitive closure. Psychology \& Marketing, 21(9), 739-753. doi:http://dx.doi.org/10.1002/mar.20027

Kemp, S. (1998). Perceiving luxury and necessity. Journal of Economic Psychology, 19(5), 591606. doi:http://dx.doi.org/10.1016/S0167-4870(98)00026-9

Kemp, S., \& Bolle, F. (1999). Preferences in distributing scarce goods. Journal of Economic Psychology, 20(1), 105-120. doi:http://dx.doi.org/10.1016/S0167-4870(98)00045-2 
Kenward, B., \& Dahl, M. (2011). Preschoolers distribute scarce resources according to the moral valence of recipients' previous actions. Developmental Psychology, 47(4), 1054-1064. doi:http://dx.doi.org/10.1037/a0023869

King, L. A., Hicks, J. A., \& Abdelkhalik, J. (2009). Death, life, scarcity, and value: An alternative perspective on the meaning of death. Psychological Science, 20(12), 14591462. doi:http://dx.doi.org/10.1111/j.1467-9280.2009.02466.x

Kirshner, S., Weiss, P. L., \& Tirosh, E. (2011). Meal-maker: A virtual meal preparation environment for children with cerebral palsy. European Journal of Special Needs Education, 26(3), 323-336. doi:http://dx.doi.org/10.1080/08856257.2011.593826

Ku, H., Kuo, C., Yang, Y., \& Chung, T. (2013). Decision-contextual and individual influences on scarcity effects. European Journal of Marketing, 47(8), 1314-1332. doi:http://dx.doi.org/10.1108/03090561311324345

Lee, S. Y., Oh, S., \& Jung, S. (2014). The effects of scarcity appeal on product evaluation: Consumers' cognitive resources and company reputation. Social Behavior and Personality, 42(5), 743-756. doi:http://dx.doi.org/10.2224/sbp.2014.42.5.743

Lynn, M. (1989). Scarcity effects on desirability: Mediated by assumed expensiveness? Journal of Economic Psychology, 10(2), 257-274. doi:http://dx.doi.org/10.1016/01674870(89)90023-8

Lynn, M. (1991). Scarcity effects on value: A quantitative review of the commodity theory literature. Psychology \& Marketing (1986-1998), 8(1), 43. doi:http://dx.doi.org/10.1002/mar.4220080105 
Lynn, M. (1992). Scarcity's enhancement of desirability: The role of naive economic theories. Basic and Applied Social Psychology, 13(1), 67-78. doi:http://dx.doi.org/10.1207/s15324834basp1301_6

Lynn, M., \& Bogert, P. (1996). The effect of scarcity on anticipated price appreciation. Journal of Applied Social Psychology, 26(22), 1978-1984. doi:http://dx.doi.org/10.1111/j.15591816.1996.tb01783.x

Paulus, M., \& Moore, C. (2012). Producing and understanding prosocial actions in early childhood. Advances in Child Development and Behavior, 42, 271-305. doi:10.1016/B9780-12-394388-0.00008-3

Rand, D., Katz, N., \& Weiss, P. L. (2007). Evaluation of virtual shopping in the VMall: Comparison of post-stroke participants to healthy control groups. Disability and Rehabilitation: An International, Multidisciplinary Journal, 29(22), 1710-1719. doi:http://dx.doi.org/10.1080/09638280601107450

Rand, D., Weiss, P. L., \& Katz, N. (2009). Training multitasking in a virtual supermarket: A novel intervention after stroke. American Journal of Occupational Therapy, 63(5), 535542. doi:http://dx.doi.org/10.5014/ajot.63.5.535

Rao, N., \& Stewart, S. M. (1999). Cultural influences on sharer and recipient behavior: Sharing in Chinese and Indian preschool children. Journal of Cross-Cultural Psychology, 30(2), 219-241. doi:http://dx.doi.org/10.1177/0022022199030002005

Rizzo, M. T., \& Killen, M. (2016). Children's understanding of equity in the context of inequality. The British Journal of Developmental Psychology, 34(4), 569-581. doi:http://dx.doi.org/10.1111/bjdp.12150 
Rummel, A., Howard, J., Swinton, J. M., \& Seymour, D. B. (2000). You can't have that! A study of reactance effects \& children's consumer behavior. Journal of Marketing Theory and Practice, 8(1) 38-45. doi: http://dx.doi.org/10.1080/10696679.2000.11501859

Schug, M. C. (1987). Children's understanding of economics. The Elementary School Journal, 87(5), 507-518. doi:http://dx.doi.org/10.1086/461513

Shaw, A., Choshen-Hillel, S., \& Caruso, E. M. (2016). The development of inequity aversion. Psychological Science, 27(10), 1352-1359. doi:http://dx.doi.org/10.1177/0956797616660548

Siegler, R. S., \& Thompson, D. R. (1998). "Hey, would you like a nice cold cup of lemonade on this hot day": Children's understanding of economic causation. Developmental Psychology, 34(1), 146-160. doi:http://dx.doi.org/10.1037/0012-1649.34.1.146

Snyder, C. R. (1992). Product scarcity by need for uniqueness interaction: A consumer catch-22 carousel? Basic and Applied Social Psychology, 13(1), 9-24. doi:http://dx.doi.org/10.1207/s15324834basp1301_3

Strauss, A. L. (1952). The development and transformation of monetary meanings in the child. American Sociological Review, 17, 275-286. doi:http://dx.doi.org/10.2307/2088073

Suri, R., Kohli, C., \& Monroe, K. B. (2007). The effects of perceived scarcity on consumers' processing of price information. Journal of the Academy of Marketing Science, 35(1), 89100. doi:http://dx.doi.org/10.1007/s11747-006-0008-y

Tian, K. T., Bearden, W. O., \& Hunter, G. L. (2001). Consumers' need for uniqueness: Scale development and validation. Journal of Consumer Research, 28(1), 50-66. doi:http://dx.doi.org/10.1086/321947 
Tkhorzhevskii, V. V. (1972). Heuristic thinking in preschool children. Voprosy Psychologii, 152153. Retrieved from http://ezproxy.lib.ryerson.ca/login?url=http://search.proquest.com/docview/615888500?acc ountid=13631

Towse, J. N., Loetscher, T., \& Brugger, P. (2014). Not all numbers are equal: Preferences and biases among children and adults when generating random sequences. Frontiers in Psychology, 5, 7. doi:http://dx.doi.org/10.3389/fpsyg.2014.00019

van Herpen, E., Pieters, R., \& Zeelenberg, M. (2014). When less sells more or less: The scarcity principle in wine choice. Food Quality and Preference, 36, 153-160. doi:http://dx.doi.org/10.1016/j.foodqual.2014.04.004

Van Petegem, S., Soenens, B., Vansteenkiste, M., \& Beyers, W. (2015). Rebels with a cause? Adolescent defiance from the perspective of reactance theory and self-determination theory. Child Development, 86(3), 903-918. doi:http://dx.doi.org/10.1111/cdev.12355

Verhallen, T. M. (1982). Scarcity and consumer choice behavior. Journal of Economic Psychology, 2(4), 299-322. doi:http://dx.doi.org/10.1016/0167-4870(82)90034-4

Verhallen, T. M. M., \& Robben, H. S. J. (1994). Scarcity and preference: An experiment on unavailability and product evaluation. Journal of Economic Psychology, 15(2), 315-331. doi:http://dx.doi.org/10.1016/0167-4870(94)90007-8

Warneken, F., \& Tomasello, M. (2007). Helping and cooperation at 14 months of age. Infancy, 11, 271-294. doi:http://dx.doi.org/10.1111/j.1532-7078.2007.tb00227.x

Woller, K. M. P., Buboltz, W. C., Jr., \& Loveland, J. M. (2007). Psychological reactance: Examination across age, ethnicity, and gender. The American Journal of Psychology, 120(1), 15-24. Retrieved from 
http://ezproxy.lib.ryerson.ca/login?url=http://search.proquest.com/docview/621693530?acc ountid=13631

Worchel, S. (1992). Beyond a commodity theory analysis of censorship: When abundance and personalism enhance scarcity effects. Basic and Applied Social Psychology, 13(1), 79-92. doi:http://dx.doi.org/10.1207/s15324834basp1301_7

Worchel, S., Lee, J., \& Adewole, A. (1975). Effects of supply and demand on ratings of object value. Journal of Personality and Social Psychology, 32(5), 906-914.

doi:http://dx.doi.org/10.1037/0022-3514.32.5.906

Wright, R. A. (1992). Desire for outcomes that are more and less difficult to attain: Analysis in terms of energization theory. Basic and Applied Social Psychology, 13(1), 25-45. doi:http://dx.doi.org/10.1207/s15324834basp1301_4

Wynn, K. (1992). Addition and subtraction by human infants. Nature, 358(6389), 749-750. doi:http://dx.doi.org/10.1038/361374a0

Wynn, K. (1998). Psychological foundations of number: Numerical competence in human infants. Trends in Cognitive Sciences, 2(8), 296-303. doi:http://dx.doi.org/10.1016/S13646613(98)01203-0

Yu, J., Zhu, L., \& Leslie, A. M. (2016). Children's sharing behavior in mini-dictator games: The role of in-group favoritism and theory of mind. Child Development, 87(6), 1747-1757. doi:http://dx.doi.org/10.1111/cdev.12635 